\title{
Synergy of a complex of complex technologies of the future agro-industrial complex
}

\author{
Igor Bakin ${ }^{1, *}$, Viktor Panfilov ${ }^{2}$, and Anatoliy Popov ${ }^{1}$ \\ ${ }^{1}$ Kemerovo State University, Krasnaya Str., 6, 650043 Kemerovo, Russia \\ ${ }^{2}$ Russian State Agrarian University - Moscow Timiryazev Agricultural Academy, Timiryazevskaya \\ Str., 49, 127550 Moscow, Russia
}

\begin{abstract}
Considering a synergistic approach to the development of complex technologies for the production of the agro-industrial complex is considered. An analysis of the prospects for the unification of manufacturing and processing industries is given. The features of the structure of simple, small, large and complex technological systems are described. The influence of the stages of digitalization in the new synergetic picture of the agricultural complex is revealed. To effectively use the existing capacities of agrarian and food technologies and predict their further development, a qualitative change in the state of the entire complex system of the complex is considered, to identify control parameters and the least stable modes. The development of technological processes is considered taking into account the synergistic effects of interaction. Bifurcation transitions on the way of obtaining products and system-forming factors of the organization of complex technological production systems are described. The influence of internal and external relations on the structure of small and large systems of processing and food industries is analyzed.
\end{abstract}

\section{Introduction}

A characteristic trend in the development of modern technological civilization is the development and creation of extremely complex systems [1]. This trend extends to the technologies of the agro-industrial complex (AIC). The prospect of such technologies is seen in the unification of manufacturing and processing technologies, that is, the creation of endto-end branching technologies for food production. The integration of industrial forms of production is explained by the complication of a set of interrelated elements - tools of labor, means and procedures of management, as well as functional relations [1].

Complex systems are characterized by a hierarchical structure and include simple, small and large systems. Simple systems in technology are separate various processes of transformation of the food environment. Small technological systems are autonomous groupings of simple systems in which there is a stochastic interaction of individual processes. Small systems - production areas, implementing local technologies. The integration of small systems into large ones is characterized by the emergence of separate agricultural processing technologies. They have completely new features. Complex systems have an even more

\footnotetext{
${ }^{*}$ Corresponding author: bakin@kemsu.ru
} 
complex integrity than their constituent large systems. They are characterized by openness, as well as energy, material and informational connections with the environment. Examples of large systems in agriculture are modern technologies for growing, harvesting and storing crop products and modern technologies for producing livestock products, and in the processing and food industries, these are technological lines. Complex technologies represent the next system-forming level of development of productive forces, in comparison with large systems.

Analysis and forecast of the development of complex technologies in the agro-industrial complex allows the branch of scientific knowledge - synergetic. From the standpoint of synergy, a complex technology in the agro-industrial complex is an open, non-linear, nonequilibrium system of technological processes for the production and processing of agricultural products in order to obtain food. This system has two distinct zones of bifurcation: the transition from agricultural production to storage and the transition from storage to processing. Both zones are characterized by significant changes in the material and energy backbone factors.

Important to adhere by that complexity is an essential characteristic of the evolution of artificial systems, that is, each subsequent level is more complex than the previous one. Moreover, the development of a complex system is an increase in orderliness and is expressed in the qualitative improvement of the system, an increase in the level of its organization. At the same time, it should be borne in mind that the modern methodology of scientific research, based on the systems approach, cybernetics and synergetic, is still in its infancy.

A systematic methodology that provides methods for understanding the complex holistic process of food production is becoming an urgent direction in solving promising scientific and technological problems of the agro-industrial complex. Linear thinking, characteristic of the study of simple, small and even large systems, can be unacceptable in a non-linear complex reality. This kind of thinking can lead to failure in exploring complex systems and making diagnoses in order to improve and develop complex technology. The fact is that, unlike the traditional practice of organizing large systems, the development of complex systems solves a number of the following issues. When creating complex end-to-end technologies, the mechanisms of phenomena and the regularities of individual technological processes of transforming the initial food environment in simple, small and large systems are considered to a lesser extent, and to a greater extent - the regularities of organization and functioning, taking into account the influence of the external environment. When scaling agricultural technologies, one should focus more on positive links that give rise and development of the entire system.

The purpose of the study is to show the decisive role of system-forming factors in the organization of complex technologies of the future agro-industrial complex of Russia at the present stage of development, to describe the bifurcation transitions of complex technological systems of the agro-industrial complex, to identify the control parameters of the organization of complex technological production systems.

\section{System-forming factors of complex technological systems}

A synergistic approach to the organization of complex agro-industrial complex technologies requires a search and formulation of system-forming factors. The system-forming factor is the factor that forms the system. The search for a system-forming factor is the main problem in organizing a complex technology, since, having found it, it is possible to delimit the system from the environment.

The search for the backbone factor of a complex technology can be carried out in two directions. The first is followed by specialists from certain branches of the agro-industrial complex. Agricultural specialists investigate the specifics and nature of the system-forming 
factors in each technology that produces products of plant and animal origin, as well as their storage. Specialists of the processing industries, whose technologies disassemble agricultural products into anatomical parts and ensure their storage, also follow the first path. Food production specialists follow the same path, who in their technologies, in accordance with the recipe, collect the anatomical parts of plants and animals into a finished food product and store it until sale [2]. Thus, each agro-industrial complex technology is provided with its "own" system-forming factor.

In the second variant, the backbone factor determines the general functions of the development of all technologies of a complex system. The possible development of the system is determined by the duration of the processes and its part - the future. Improving the efficiency of a complex agro-industrial complex system is the goal of the future. The mutual reinforcement of large technologies connected into a whole is manifested in the form of a synergistic effect of the functioning of complex systems. The interaction of the backbone factors of different technologies also leads to the development of a complex, integral technology of processing industries.

\section{Evolution of internal backbone factors}

The connection between the elements of a large technological system (technological processes) is provided by internal system-forming factors. The same internal system-forming factor exists in a complex technology between its elements. These internal connections can be of the following types: interaction, structure, functioning, management, and development.

For the conditions of industrial production, the concept of multilateral connections between cyber-physical systems and people was formulated in 2011 in the form of the postulates of Industry 4.0 technology, put forward as a national strategy for the development of science and technology in Germany [3]. The development of sophisticated technologies has implied vertical linkages of individual enterprises along the entire product chain and horizontal links of production processes and machines within enterprises. Interaction and control connections were based on digital integration of production processes through adaptive, evolutionary and self-organizing networks [4]. Co-creation of products based on new technologies and communications gave an advantage to small and medium-sized enterprises with limited resources, which alone lacked the capabilities and skills to do this. The synergistic effect of innovation in manufacturing and operating systems contributes to faster, customized production and optimization of the manufacturing process. Integration benefits include fine-tuning the product, improving product quality, traceability and process control. Vertical links between retailers and agricultural producers enable a faster response to new consumer demands through a range of technological innovations that improve the functionality, properties and quality of the supplied products [4].

Considering the development of the system of manufacturing and processing industries, experts of the international community in 2017 [5] formulated a forecast for sustainable development of the agro-industrial complex until 2030. It was based on the analysis of the main problems and trends in the development of food systems. However, after a short time, the development of technologies led to the manifestation of competition in a complex nonlinear system, which was expressed in the integration of various structures and the emergence of new attractors described in 2018 in the study of the food technology industry FoodTech.

The distribution and implementation of online platforms in the areas of technological solutions in agricultural production (FoodScience, AgTech) and the globalization of the food distribution system as a whole (Delivery \& Retail, Food Service, Media) became a new system-forming factor in the development of technologies for the future of the agro-industrial complex. The change in the spatio-temporal dynamics of the parameters of the system was 
reflected in the global FoodNet market and the Russian sector of agricultural and processing industries in the form of the concept of a digital platform for the food and personalized food market "Foodnet" within the framework of the National Technological Initiative (NTI), under the national project "Science". Scientific and technological innovations in the processing industries, or otherwise "end-to-end" technologies, have changed the structure of traditional industries based on related high-tech products and services.

Connections of interaction, management and development of complex nonlinear systems of the agro-industrial complex with the introduction of digital technologies have determined the evolutionary development of the system. One of the effects of the transition to information and communication technologies was a change in the structure of production in the agro-industrial complex, in which productivity growth is not associated with an increase in agricultural areas and volumes. According to Rosselkhozbank experts, the introduction of digital agricultural technologies in the world will increase the profitability of the agroindustrial complex by more than 500 billion rubles in the next five 5 years. However, for the Russian agricultural sector, the change in the production paradigm is much slower, the number of modern technologies being introduced is up to $5 \%$ of enterprises. The forecast scenario of the Ministry of Agriculture of the Russian Federation assumes an increase in the Russian market of digital technologies in the agro-industrial complex from 360 billion rubles fivefold by 2026 . The economic effect is expected to be achieved using the Internet of things, the introduction of information and production technologies, developments in the field of biotechnology and new materials.

The influence of management ties can be traced by analyzing the dialectics of the development of Russian manufacturing and processing technologies of the system complex "Agricultural and food technology" [1], where the leading role is assigned to the internal state policy and regulation in the sphere of the agro-industrial complex. A possible scenario for sustainable development of the agro-industrial complex with state support, developed by the Higher School of Economics, involves the expansion of the domestic market by reducing external imports and balanced regulation of the industry. Overcoming import dependence is associated with developments in the field of "precision" agriculture, agro telematics and robotization, information and biotechnology.

Smart products are considered as systems consisting of natural objects, artificial subsystems and controllers [6]. Their integrity is ensured by the internal interaction between the elements of the system and external relations with consumers, as well as a certain autonomy.

The development of "precision" and "smart" agriculture is aimed at creating links between automated enterprise management systems, systems for accounting and certification of products. The implementation of a modern complex intellectual system was the national digital platform of the Ministry of Agriculture of Russia. Its goal is to ensure the comprehensive digitalization of the agro-industrial complex, the use of digital services on one site, and the creation of a common industry data base. The creation of the system is aimed at standardizing and digitalizing technologies, increasing productivity and environmental friendliness in the structure of agricultural processing industries. A separate area of the platform is the task of control (monitoring) and labeling of agricultural products. The use of technologies of unmanned aerial and near-earth space systems in agriculture provides accurate mapping and accounting of farmland, monitoring of the condition and control of crops. Analysis of information arrays using Big Data and artificial intelligence (AI) is used in the segment of "smart" farming to predict crop yields based on data on climate change, soil, plant appearance and other parameters.

Management connections are highlighted at the stages of implementation of small automation and robotization systems for "smart" agriculture. Global manufacturers of agricultural equipment (CaseIH and $\mathrm{CNH}$ Industrial (USA), in cooperation with the 
company-developer of navigation systems Trimble Inc. (TRMB); Japanese Yanmar Holdings Co., Ltd .; John Deere; Cognitive Technologies (Russia), etc. ) developed unmanned tractor models of various functions for the mass market. The emergence of new technology is aimed at increasing the intensity of production, simplifying the functions of farm management and, in general, replacing industrial agricultural technologies.

The internal connections of the structure of the system determine the use of digital twins, when based on the flows of digital information about the change or use of the product, a response and control strategy is developed [7].

The destruction of linear connections from producer to consumer through retail chains or food enterprises occurred with the emergence of digital online platforms (Wolt, Deliveroo, etc.). New technologies have led to the connection of production, preparation and delivery of food products directly to the consumer, taking into account his preferences and diet. The forecasts for the growth of the Russian food technology market (Foodtech) are estimated at $20-30 \%$ per year. Links in the fields of medicine, food technology, nutrition, dietetics, marketing and logistics have propelled the emergence of the personalized nutrition industry. An interdisciplinary field of science - nutrigenomics, which studies the relationships between interactions between human genes, environmental factors, such as nutrition, health status, has given rise to new technologies in the field of specialized products [8].

The qualitative restructuring of processes in the agro-industrial complex system is conditioned by the system-forming factor that arose during the massive introduction and use of nanotechnology. This governing mechanism provides new functions and connections in food and feed processing and production, packaging, transportation, analysis and control methods, and other areas.

New technologies for treating plants using pesticides and herbicides have emerged with the advent of nano-encapsulation and controlled release methods on an ultra-small scale, usually from 1 to $100 \mathrm{~nm}$ [9]. Nanoscale delivery systems are applied to nutrient growth regulators directly in plant tissue. The introduction of agricultural nanotechnology solves the problem of increasing yields and improving varieties, ensuring their sustainability.

Technologies for nanoencapsulation of valuable compounds (vitamins, minerals, antimicrobial drugs, drugs, dyes, antioxidants, probiotics, etc.) have been proposed to be used to provide the body with them for long periods of time [10]. Systems for the delivery and release of particles have been developed under certain environmental factors.

The synergistic effect of nanotechnology processes with biotechnology and information technology has manifested itself in the development of nanobiosensors for the detection of pathogens and contaminants in food systems. Nano-biosensors are used in agriculture to determine a wide range of materials, including fertilizers, herbicides, pesticides, insecticides, pathogens, moisture, soil $\mathrm{pH}$, etc. [11].

The introduction of nanoparticles into packaging materials ensures the preservation, extension of the shelf life and the quality of the product. The bonding of particles is carried out at the level of the packaging material, its part or inside the container. Active protection of food products from external conditions is provided by the absorption of various substances (oxygen, moisture, etc.) or their release (antioxidants, carbon dioxide, antimicrobial agents, etc.) [12]. Communication of information exchange with the external environment of intelligent packaging systems is based on the functions of nanosensors embedded in packaging materials used to receive and transmit data on the quality and safety of packaged food.

A new qualitative change in biological characteristics with a change in the bonds and systems of nanoparticles underlies the technology of genetically modified production [10]. According to research by the Russian Agricultural Bank, the market for products obtained using genetic modification will amount to $\$ 9.7$ billion by 2025 . Technological solutions of 
genetic engineering have given perspectives for adaptive areas of crop breeding, genetically engineered modification of farm animals, and synthetic biology technologies.

Bioproduct Engineering encompasses the related fields of biotechnology, modeling and food systems. Studying the relationships between the chemical composition and properties of raw materials, processing technologies allows you to create products with specified properties and purposes. The development of new types of organic products is based on connections from the molecular level to the macro-level of manufacturing enterprises and the mega-level of distribution networks [13].

\section{Evolution of external backbone factors}

In addition to internal connections, a complex technology has external connections that contribute to the emergence, formation and development of such technology. But external connections can also be systemic. These links are aimed at destabilizing and losing the stability of the system. In this case, the backbone connections are unable to maintain the adaptability of a complex technology. The destruction of the system occurs when external factors prevail. The manifestation of a resonance of external disturbances and internal connections is possible, as a result of which negative consequences are manifested in processing technologies. At the same time, even a small fluctuation in the functioning of technology can serve as an impetus for its development in a completely new, innovative direction.

The sequence of technological advances in the Fourth Industrial Revolution led to the development of new types of organizations and structures. The links between the real (physical) and digital world are shrinking and blurring [14]. Digital technologies are becoming the decisive system-forming link of globalization. The previously listed systemic factors (climate change; growth in the world population and megalopolises; decrease in biological, water and raw materials; impoverishment of the population, etc.) are being changed by digital technologies, which are becoming a global instrument of economic impact.

New technological solutions arise when a qualitative transformation of the system parameters, or otherwise, when a bifurcation event occurs. The future development of technologies is a probabilistic parameter of the ambiguity of the development of the system [1].

Considering the qualitative restructuring of the food market in the areas of Food Service, Delivery \& Retail and Media, one can trace the evolutionary impact of individual fluctuations on the transformation of a complex system. An example of the adaptation of the system of services and public catering products is the development of the previously popular organizational structures "home kitchen", "kitchen factories" into the format of the "dark kitchen" restaurant business. Well-known technological approaches to the processing of raw materials into semi-finished products have been developed into high-margin production based on online services and interaction with food delivery aggregators. Products are developed only for delivery to the consumer, from a limited range of raw materials, but according to a varied menu that meets the needs of the buyer. Cost optimization is achieved with less floor space and less overhead. The rapid growth of this public catering sector occurred during a pandemic and imposed restrictions on the catering industry. New food production and delivery format continues to scale and improve efficiency.

Global factors such as climate change and world population growth mean that traditional farming methods may not be able to meet the expected growth in food demand. In this regard, alternative agro-industrial development and production strategies arise. New technologies of cell agriculture are aimed at the production of renewable agricultural products in bioreactors using cells of microorganisms, animals or plants [13]. 
For the system of the national agro-industrial complex, destabilizing effects are the consequences of the global financial and economic crisis and the increasing world instability [14]. Technologies for the extensive development of domestic agro-industrial production cannot be competitive on the world food markets, given the dumping conditions of global corporations. To maintain the stability of the system, a balanced regulation of domestic markets for agricultural raw materials and food is required, in accordance with the mechanisms for ensuring food security of the Russian Federation.

External factors of direct and indirect government intervention in the activities of enterprises are expressed in the environmental regulation of production. The imposed restrictions, on the one hand, reduce competitiveness and market advantages [15], on the other hand, enterprises introduce environmental innovations.

The transition to "green" technologies includes the creation of new environmentally friendly products, reducing energy costs, reusing products and raw materials, reducing environmental pollution throughout the entire production cycle through technological improvements [16]. Consumers prefer sustainable products based on a newly formed mindset and a desire for technological advancement.

The introduction of innovative industrial technologies in the agriculture sector [17] is aimed at: automating data collection and monitoring along the entire value chain; increasing the flexibility and intensity of production facilities; reducing the number of errors and costs; improving product quality and the ability to meet customer needs.

\section{Discussion}

The evolution of agro-industrial complex technologies is an example of development from simple to complex, from lower forms of organization to higher, that is, developing, technologies of the agro-industrial complex acquire an increasingly complex organization. In the new synergistic picture of the agro-industrial complex, the priority will be:

- behind the mechanism for creating interdependent elements that make up a developing integral system (complex technology);

- behind a coordinated innovative flow in space and time of several processes, which manifests itself during their addition;

- behind the increasing complexity of technology, which is an open, nonlinear, no equilibrium system.

Water is a system-forming substance of a large system for the production of biological raw materials and its processing to products, the amount of which, the state and forms of interaction with other substances and components of biological objects determine the development of living organisms. The energy factor is heat. A rational amount of heat energy ensures the rational development of organisms of biological origin, their storage before processing, as well as the formation of the quality of finished products. The information factor, the most complex one, is presented as a subjective perception by a person of the state of the first two factors and his management of these factors. The information factor controls the previous two and its subjectivity has long been an obstacle to the development of complex systems. Modern technology development requires a person to be completely withdrawn from the decision-making system for the development and functioning of less complex systems for the production of agricultural products, their storage and processing into food. At the same time, ensuring the stability of the exchange of matter and energy requires maximum isolation of the agricultural production system from the influence of natural factors (weather conditions, etc.) Thus, the unity of three closed systems can be organized: production of agricultural products, storage and processing. 


\section{Conclusions}

1. Modern technologies of the agro-industrial complex are on the verge of accelerated development due to the introduction of digital technologies. There has been a transformation of traditional raw materials processing technologies with the advent of digital products and services. The internal communications of the system, under the influence of digitalization, have provided new functions of cooperation and competition.

2. Digital transformation, on the one hand, destroys existing processes and connections, on the other hand, generates innovation, the creation of new values and business ecosystems. New technologies are more focused on external communications and networking. The digital transformation of complex agro-industrial complex systems is critical, giving new meaning to the value chain of agricultural products.

\section{References}

1. V. A. Panfilov, Food Processing: Techniques and Technology, 50(4), 642 (2020)

2. A. L. Maytakov, E. G. Vinogray, L. N. Beryazeva, Advances in Social Science, Education and Humanities research, 273, 238 (2019)

3. M. Bernhard, H. Otthein, Industry 4.0 and Urban Development - The Case of India. acatech Materialien (2015)

4. M. J. Oltra-Mestre, V. Hargaden, P. Coughlan, Creat Innov Manag, 1 (2020)

5. The future of food and agriculture: Trends and challenges, http://fao.org

6. T. Dickopf, A. Hristo, P. Müller, J.Göbel, S.Forte, Procedia CIRP, 84, 538 (2019)

7. D. M. Maio, G.D. Kapos, N. Klusmann, In: 4th IEEE International Symposium on Systems Engineering, ISSE (2018)

8. L. R. Ferguson, M. P. Barnett, Nutrition \& Dietetics, 69, 198 (2012)

9. A. Gogos, K. Knauer, T.D. Bucheli, Food Chem., 60(39), 9781 (2012)

10. L. Rashidi, K. Khosravi-Darani, Food Sci. Nutr., 51(8), 723 (2011)

11. C. Bartolucci, In Nanotechnology in Agriculture and Food Science (2017)

12. G. Nathalie, P. Stéphane, M.L. Jose, E. Yolanda, G. Carole, In Nanotechnology in Agriculture and Food Science (2017)

13. G. Gubser, S. Vollenweider, D. Eibl, R. Eibl, Eng Life Sci., 1 (2020)

14. J.-P. Dal Pont, In Process Industries, 2 (2020)

15. D. Lee, International Journal of Environmental Research and Public Health, 17, 2274 (2020)

16. J. Álvarez Jaramillo, J. W.Zartha Sossa, G. L. Orozco Mendoza, Business Strategy and the Environment, 28, 512 (2019)

17. G. Büchi, M. Cugno, R. Castagnoli, Technological Forecasting and Social Change, 150 (2020) 